\title{
Dynamic Life Tables for India and Some of Its Major States
}

\author{
Mompi Sharma ${ }^{1}$, Labananda Choudhury² \& Rajan Sarma ${ }^{3}$
}

The concept of dynamic life tables arises when the mortality experience of the period life table cohort does not remain the same. This idea was proposed first by Denton and Spencer (2011) and allows for the possibility of further decline in mortality in period life tables. Developing countries, like India, have also been experiencing continuous declines in mortality rates for more than two decades. As such, this examines the pattern of mortality and also the life expectancy of India and some of its selected states for the period 2006-2010 if the observed mortality rates changes over the previous 10, 25 and 50 years. This paper also formulates temporary life expectancy under dynamic consideration and thereby measures the change in dynamic life expectancy between two exact ages. Analysis shows that dynamic life expectancies at birth are higher in comparison to those observed through the typical procedure in India and the states under consideration. Interestingly, the effects of the dynamic calculations are mostly seen in older age groups, which can also be found from the dynamic temporary life expectancy for these age groups.

Keywords Dynamic life expectancy; dynamic temporary life expectancy

\section{Introduction}

In demography, the concept of dynamic life tables comes from the necessity to incorporate the effect of the year of death into the estimation of the measurement of mortality (Debon, Montes \& Sala, 2006). A review of dynamic models and their comparison can also be found in Debon et al. (2006). Further, the modelling and projection method developed by Lee and Carter (1992) is the most commonly used method of projection. However, in the present paper the 'dynamic life table' applies only if the observed mortality rates of the period life tables continue to change and should not be used for forecasting (Denton \& Spencer, 2011).

Life tables are useful in analyzing changes in the mortality experienced by a population through time (Bell \& Miller, 2005). Since period life tables are based on mortality rates observed during a given year (or period), the life expectancies from such a table can reflect long-term implications of recent behaviour, but does not relate to the experience of any real cohort and typically varies from year to year as death rates change (Schoen \& Canudas-Romo, 2005). As Richards and Donaldson (2010) explain, mortality data for period tables is taken as observed, not adjusted for future changes, and the tables are not forward-looking in the sense that future improvement in mortality is not incorporated.

However, records in both developed and developing countries show a continuous decline in mortality. An extension of the period life table, then, namely a 'dynamic' extension, created by Denton and Spencer (2011) allows for the possibility of further changes in probabilities of death. This extension has been demonstrated with Canadian mortality data. Continuing the

\footnotetext{
1 Department of Statistics, Gauhati University, Guwahati, India

2 Department of Statistics, Gauhati University, Guwahati, India

${ }^{3}$ Department of Statistics, Darrang College, Tezpur, India. Email: srmrjn@gmail.com
} 
work of Denton and Spencer (2011), researchers can attempt to show what would happen to the cohort of a period life table of a developing country like India if the mortality conditions pertaining throughout its life will tend to change.

The historical record of Indian mortality data reveals a rapid demographic change over the years. The country's demographic transition began, rather hesitatingly, with a reduction in the average death rate during the 1920s and 1930s (Dyson, 2008). According to the bulletins of Sample Registration System (SRS) of India, death rate has declined from 14.9 per thousand in 1971 to 7.1 in 2011. The infant mortality rate, which is an important indicator of health status of a country, has also registered a significant decline from 129 per one thousand live births in 1971 to 40 in 2013 (SRS, 2014). Due to a decline in mortality rates, the life expectancy at birth has also increased from 49.7 years during the period 1971-75 to 67.5 years in 2009-13 (SRS, India).

When life expectancy improves, it is nearly always the result of progress in survival among both children and adults, but the relative contribution of the different age groups changes according to the stage of demographic transition (Yamunadevi \& Sulaja, 2016). The demographic transition is characterized by mortality decline among all age groups, with reductions in death rates among children dominating survival improvements in the early stages of the transition and mortality decline among older adults becoming increasingly dominant in the advanced stages of the transition (United Nations, 2012).

This is demonstrated in Indian demographic data, where the size of the older population has risen from 12.1 million in 1901 to approximately 77 million in 2001, according to Census figures (Central Statistics Office, 2011). Yamunadevi and Sulaja (2016) have examined the changes in old age mortality in India from 1971 to 2011 and revealed that the mortality at old age has considerably declined over time.

Although India has witnessed a spectacular improvement in mortality, the changes in mortality conditions across its states have been different. Moreover, the regional differentiation in adult mortality is significantly smaller than that of child mortality. For instance, the southern states experienced significantly lower levels of child mortality, whereas the adult mortality appears to be somewhat lower in the north-western parts of the country (Bhat, 1987). With continuous changes in mortality, numerous studies (Chaurasia, 2010; Navaneetham, 1993; Saikia, Jasilionis, Ram, \& Shkolnikov, 2009) have assessed the trends and levels of mortality transition and expectation of life for India and its states. Nevertheless, all of these studies have been based on the assumption that the mortality rates of the period life table remain the same. So far, no studies in India have attempted to incorporate these continuous changes in mortality.

Since we expect changes in mortality over time among all ages and also the continuous decline in infant and old age mortality, we chose to examine mortality by using dynamic life tables. The need for analysis through the use of the dynamic life table is particularly important for India and some of its major states to paint a more accurate picture of demographic shifts. To have an idea about the pattern of probabilities of death and corresponding life expectancies, mortality data from different states were selected from the North, South, East, West, Central and Northeast zones of India. For the present study, this includes Rajasthan and Punjab from North, Kerala from South, West-Bengal from East, Maharashtra from West, Uttar Pradesh from Central and Assam from Northeast zones.

Additionally, the pace of mortality reduction and consequently the increase in life expectancy is different over the last four decades. The rise in life expectancy at birth in India during the 30 years from 1970-75 through 2001-05 has been slow (Chaurasia, 2010). A study by Bhat and Navaneetham (1991) examines the speed of mortality decline during the period of 1970-88 and 
its variation among the states of India. As such, in order to show the historical change in mortality in India and its states, we consider periods of 10, 25 and 50 years. Thus, our aim is to provide dynamic life expectancies for India and some of its major states (mentioned above) for the period 2006-2010 based on the rates of change of probabilities of death over the previous past10, 25 and 50 years (i.e., 1996-2000, 1981-1985 and 1951-1961, respectively).

It is possible to summarize mortality rates in many ways. Relatively simple measures are expectation of life and the temporary expectation of life. The term 'temporary life expectancy,' which is the life expectancies between two specific ages, was first introduced by E. Arriaga (1984) and thereby it has been used widely across the literature (Arriaga, 1984; Pollard, 1988; Saikia et al., 2009). Arriaga (1984) showed that the use of temporary life expectancy could avoid two types of problems in mortality analysis. First, the precision of life expectancy estimates based on unreliable data can be affected by errors in old age, which makes estimation of overall life expectancy at birth questionable (Saikia et al., 2009). Second, the effect of the limit of the human life span on possible change in life expectancies should be taken into account when interpreting the observed change in life expectancies (Arriaga, 1984). Following the same idea, it is important to explore the changing mortality scenario in terms of temporary life expectancies. More specifically, the temporary life expectancies under dynamic consideration will condense information on the changing mortality schedule between any two ages considerably. As such, we extend the formula for temporary life expectancy to suit the dynamic life table and shall apply it to India and the above mentioned states.

\section{Data}

The required data for this study were obtained from the Sample Registration System (SRS) based abridged life tables. The SRS is a large-scale demographic sample survey based on the mechanism of a dual record system with the objective of providing reliable estimates of fertility and mortality indicators at state and national levels for rural and urban areas separately. The SRS based abridged life tables cover a period of five years, which have been derived using the clubbed data of age-specific death rates (ASDR) for five years. Thus, estimates for the period 1981-85 may refer to the central value 1983. Similarly, the periods 1996-2000 and 2006-2010 may refer to the central values 1998 and 2008, respectively.

In the present study, to construct dynamic life tables, the period 2006-2010 is taken as the reference period and, as such, different periods over the previous 10, 25 as well as 50 years might be chosen in order to bring out the implications for maintaining the rates of change of probabilities of death for the reference period. So, the periods 1996-2000 and 1981-1985 are taken for the 10 and 25 years interval with respect to the reference period 2006-2010. There was no readily available data for the 50 years interval, however, as the SRS based abridged life tables are available only from 1970-75. In order to make comparisons over 50 years, we have taken the abridged life table for 1951-61, by Kohli (1977), which is centered at 1956. But for a 50 year gap the centered value should have been 1958. This led us to make the assumption that there is not much change in the pattern of mortality in India and its selected states within these two years (i.e., from 1956 to 1958).

However, in order to ensure comparability over 50 years, we made some adjustment to the population data for the period 2006-2010 to account for the creation of new states since 1960 . First, the data for the period 2006-2010 is adjusted for the state Punjab due to the creation of the state Haryana in 1966. Secondly, considerable adjustment is made to account for the creation of the state of Nagaland in 1963, and also of Meghalaya, Arunachal Pradesh and 
Mizoram, which were being carved out of Assam in 1972. Also the state Uttarakhand was carved out of the state Uttar Pradesh in 2000. However, as per the 2001 Census, the population of Uttarakhand contributed only the 5\% (approximately) population of Uttar Pradesh, and as such we have assumed that this does not affect comparisons made over 10 years.

During the course of preparation of this paper, SRS published the abridged life tables for the period 2009-2013, the mid-point of which is 2011. Therefore, an attempt has also been made to show the differences between the dynamic life tables of India and the states under study for the period 2006-2010 and 2009-2013. As such, for the construction of dynamic life tables for the period 2009-2013, the SRS based abridged life tables for 1999-2003 and 2009-2013 are further taken for a comparison based over 10 years.

\section{Methodology}

\section{Dynamic life table}

To construct the dynamic life table, we adopted the method as given by Denton and Spencer (2011) where two period life tables which are $t$ years apart are taken. Then the annual rate of change of probabilities of death for any age group $x$ t $o x+n$ is calculated by

$$
{ }_{n} r_{x}=\left({ }_{n} q_{x} / \bar{q}_{n}\right)^{1 / t}-1
$$

where, $\mathrm{nq}_{\mathrm{x}}$ is the probability of death for the age group $x$ to $x+n$ in the reference period table (in our context 2006-2010 will be the reference period) and $\bar{q}_{\mathrm{x}}$ is the corresponding probability in the earlier period table.

The cohort of the reference period is given by $l_{x x}$ and $l_{x y}$ is the population of initial age group $x$ to $x+n$ that survived to the age group $y$ to $y+n$. The probability that a member of the $l_{x x}$ cohort who has survived up to the exact age y will die in the interval $y$ to $y+n$ is-

$$
{ }_{n} q_{x} \overline{\bar{y}}{ }_{n} q_{y}\left(1+{ }_{n} r_{y}\right)^{y-x},
$$

where, $\mathrm{n}_{\mathrm{y}}$ is the probability of death in the age group $y$ to $y+n$ in the reference period, ${ }_{\mathrm{n}} \mathrm{r}_{\mathrm{y}}$ is the annual rate of change of that probability, and $y-x$ is the number of years between the subsequent age and initial age group, hence the number of years over which the age $y$ probability has changed (Denton \& Spencer, 2011). After obtaining the dynamic probabilities of death, the rest of the columns of the life table are calculated in the same manner as a period life table.

\section{Temporary expectation of life under dynamic consideration}

Temporary expectation of life is an index which not only helps in understanding variations in age patterns, but also facilitates comparison of different reasons for mortality (Kohli, 1977). Factors which affect mortality are associated differently with the different phases of life, and this division is useful for analytical purposes. The entire life span can be divided as infancy and childhood phase (0-5 years), adolescence phase (5-15 years), adulthood phase (15-50 years 
for the reproductive period of females and 15-60 years for the working period of males) and lastly, those ages 60 and older belong to the old age group. The temporary expectation of life between the exact ages $x a n d x+i$ is given by

$$
{ }_{i} e_{x}=\frac{T_{x}-T_{x+i}}{l_{x}} \quad \text { (Arriaga, 1984) }
$$

The dynamic temporary expectation of life between any two ages is then calculated using the same procedures as mentioned above and is given by:

$$
{ }_{i} e_{x y}=\frac{T_{x y}-T_{x, y+i}}{l_{x y}}
$$

where ${ }_{i} e_{x y}$ is the average number of years that the survivors of $l_{x x}$ cohort, alive at age $y$ will live from age $y$ to $y+i$ and $T_{x y}$ is the number of person years yet to be lived by $l_{x x}$ cohort.

\section{Results and Discussion}

Life expectancy at birth (LEB) for the period 2006-2010 and the corresponding dynamic life expectancies based on the rates of change of probabilities of death over the previous 10, 25 and 50 years, viz. 1996-2000, 1981-1985 and 1951-1961, have been presented for India and all the selected states in Tables 1 and 2 for males and females, respectively.

Table 1: Comparison of period life expectancy at birth for the period 2006-2010 with the corresponding dynamic life expectancy at birth, for India and the selected states

\begin{tabular}{|c|c|c|c|c|c|c|c|}
\hline \multirow{3}{*}{ States } & \multirow{3}{*}{$\begin{array}{c}\text { Period life } \\
\text { expectancy at } \\
\text { birth }\left(e_{0}^{0}\right) \\
2006-2010\end{array}$} & \multicolumn{6}{|c|}{$\begin{array}{l}\text { Dynamic life expectancy at birth based on rates of change of probabilities } \\
\text { of death over the previous }\end{array}$} \\
\hline & & \multicolumn{2}{|c|}{10 years } & \multicolumn{2}{|c|}{25 years } & \multicolumn{2}{|c|}{50 years } \\
\hline & & $e_{\mathrm{OO}}$ & $e_{0}^{0}-e_{00}$ & $e_{00}$ & $e_{0}^{0}-e_{00}$ & $e_{00}$ & $e_{0}^{0}-e_{00}$ \\
\hline India & 64.6 & 70.2 & 5.6 & 72.9 & 8.3 & 73.9 & 9.3 \\
\hline Assam & 61.0 & 63.0 & 2.0 & 67.7 & 6.7 & 66.5 & 5.5 \\
\hline Kerala & 71.5 & 79.4 & 7.9 & 71.6 & 0.1 & 78.1 & 6.6 \\
\hline Maharashtra & 67.9 & 76.5 & 8.6 & 76.7 & 8.8 & 74.7 & 6.8 \\
\hline Punjab & 67.4 & 68.8 & 1.4 & 69.4 & 2.0 & 76.2 & 8.8 \\
\hline Rajasthan & 64.7 & 72.3 & 7.6 & 74.8 & 10.1 & 73.9 & 9.2 \\
\hline Uttar Pradesh & 61.8 & 61.0 & -0.8 & 66.4 & 4.6 & 70.3 & 8.5 \\
\hline West Bengal & 67.4 & 75.0 & 7.6 & 78.1 & 10.7 & 73.7 & 6.3 \\
\hline
\end{tabular}
(Males)

The values in Table 1 indicate that the dynamic LEB for males in India during a 10-year interval is 70.2 years, which is 5.6 years more than the LEB of 64.6 years. The corresponding values for the intervals of 25 and 50 years are respectively 72.9 and 73.9 years, which exhibits a difference of 8.3 and 9.3 years respectively with the period LEB. A varying pace of mortality decline is observed among the selected states of India since 1970 (Navanetham, 1993), and as such substantial variation in dynamic LEB is also inevitable. Furthermore, it is significant to note that over all the intervals, the dynamic LEB are relatively higher than the period LEB for India and its states under consideration, which can also be viewed from Figure 1. This increase in dynamic LEB over all the intervals may be due to a continuous decline in mortality, which is largely the result of improved health conditions. Moreover, a growing of awareness of 
facilities for sanitation and cleanliness has helped to reduce the incidence of mortality (Panigrahy, 2006). Also the control of epidemics such as small pox, tuberculosis and malaria has reduced the death rate of India to a larger extent.

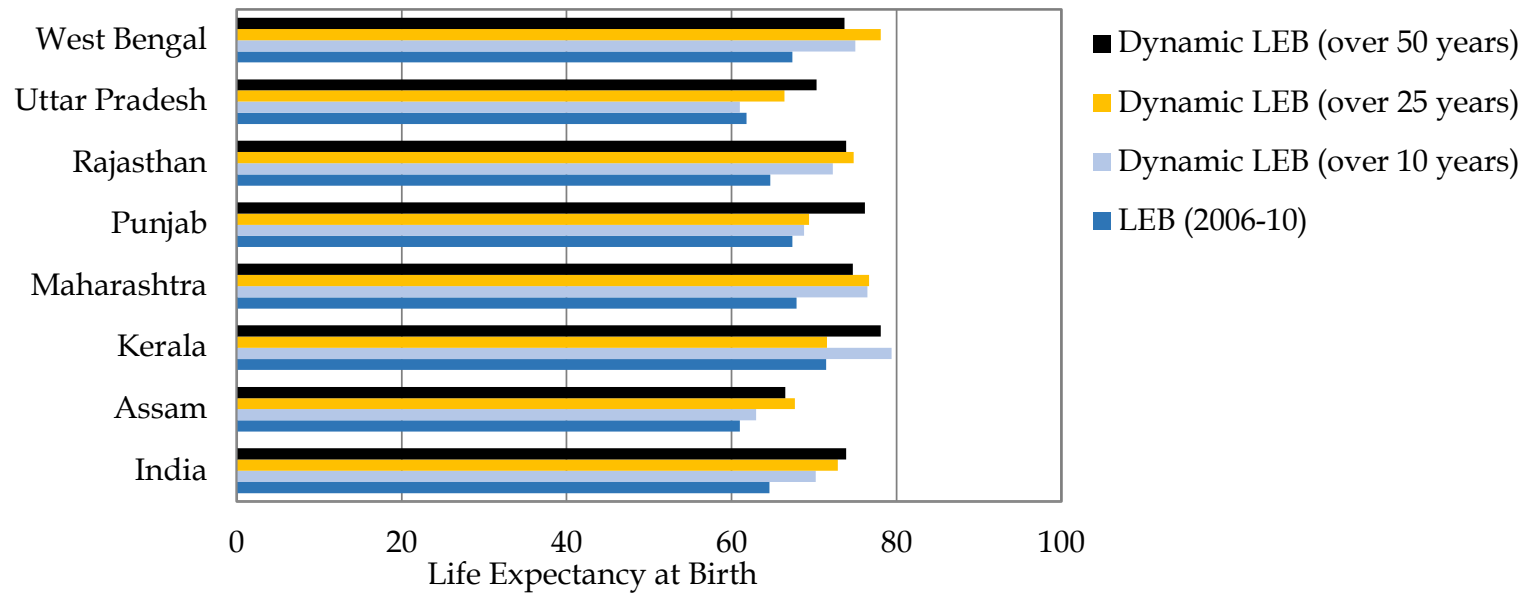

Figure 1: Dynamic and period life expectancy at birth, India and its selected states (males)

During the period between 2006-2010 and 1996-2000, the highest difference in dynamic and period LEB is observed in Maharashtra with 8.6 years and the lowest in Uttar Pradesh, where there is a negative difference of 0.8 years. This may be attributable to the fact that during this 10-year interval, there was an increase in mortality among older people in Uttar Pradesh and consequently resulted in higher dynamic probabilities of death as compared to that of the period table probabilities of death (see Appendix1). Again, for the 25- and 50-year of intervals, the greatest differences are exhibited in the states of West Bengal (10.7 years) and Rajasthan (9.2 years), whereas the least difference is seen in Kerala with less than one year and Assam with 5.5 years, respectively. This shows that variations in life expectancy at birth among the regions of India are inevitable. One of the reasons for this disparity is that the improvements in infant and child mortality have been uneven and the majority of child deaths occur within marginalized and socially disadvantaged communities (Singh, Pathak, Chauhan \& Pan, 2011). It has been found that $54.8 \%$ children ages 0-4 in EAG (Empowered Action Groups) states of India died due to major infectious diseases whereas about $60 \%$ adults ages $15-69$ years died due to major non-communicable diseases in 2001-2003 (Dubey, 2014).

Over all the three intervals, Kerala witnessed higher dynamic LEB at the 10-year interval, which indicates that the males of Kerala have experienced more declines in mortality rates during this interval than the other two intervals. Though Kerala has experienced a drastic decline in mortality and an impressive growth in life expectancy throughout the last century as a result, a major reduction occurred between 1951 and 1970 (Thomas \& James, 2014). By contrast, the states Assam, Maharashtra, Rajasthan and West Bengal have higher dynamic LEB at the 25-year interval when compared to other intervals. Likewise, the dynamic LEB for a 50-year interval is higher than the other two intervals in Punjab and Uttar Pradesh. This reflects a higher pace of decline in mortality rates during the first half century for these two states. 
Table 2: Comparison of period life expectancy at birth for the period 2006-2010 with the corresponding dynamic life expectancy at birth, for India and the selected states (Females)

\begin{tabular}{|c|c|c|c|c|c|c|c|}
\hline \multirow{3}{*}{ States } & \multirow{3}{*}{$\begin{array}{c}\text { Period life } \\
\text { expectancy at } \\
\text { birth }\left(e_{0}\right) \\
2006-2010\end{array}$} & \multicolumn{6}{|c|}{$\begin{array}{l}\text { Dynamic life expectancy at birth based on rates of change } \\
\text { of probabilities of death over the previous }\end{array}$} \\
\hline & & \multicolumn{2}{|c|}{10 years } & \multicolumn{2}{|c|}{25 years } & \multicolumn{2}{|c|}{50 years } \\
\hline & & $e_{\mathrm{OO}}$ & $e_{0}^{0}-e_{00}$ & $e_{00}$ & $e_{0}^{0}-e_{00}$ & $e_{00}$ & $e_{0}^{0}-e_{00}$ \\
\hline India & 67.7 & 75.5 & 7.8 & 78.1 & 10.4 & 77.5 & 9.8 \\
\hline Assam & 63.2 & 63.8 & 0.6 & 74.7 & 11.5 & 68.9 & 5.7 \\
\hline Kerala & 76.9 & 82.4 & 5.5 & 84.6 & 7.7 & 82.6 & 5.7 \\
\hline Maharashtra & 71.9 & 78.2 & 6.3 & 81.7 & 9.8 & 81.0 & 9.1 \\
\hline Punjab & 71.6 & 74.9 & 3.3 & 69.9 & -1.7 & 80.3 & 8.7 \\
\hline Rajasthan & 68.3 & 74.6 & 6.3 & 79.6 & 11.3 & 77.9 & 9.6 \\
\hline Uttar Pradesh & 63.7 & 68.5 & 4.8 & 74.4 & 10.7 & 73.3 & 9.6 \\
\hline West Bengal & 71.0 & 79.9 & 8.9 & 80.8 & 9.8 & 78.6 & 7.6 \\
\hline
\end{tabular}

Similar trends emerged among females as were observed among men. Table 2 reveals that the dynamic LEB of India for women produces a difference of almost 7.8, 10.4 and 9.8 years with the period LEB, respectively, for intervals of 10, 25 and 50 years. The state with the highest dynamic LEB for 10-year interval is Kerala (82.4 years), while the lowest is Assam (63.8 years). This is also the case for the 25 and 50-year gaps, where the highest dynamic LEB is in Kerala with 84.6 and 82.6 years, respectively. These have been seen lowest in Uttar Pradesh with 74.4 years and Assam with 68.9 years, respectively, for the corresponding periods.

Figure 2 clearly depicts the differences in dynamic and period LEB for females, which also varied widely across the states. During the 10-year interval, the highest difference between dynamic and period LEB is noted in West Bengal (8.9 years) and the lowest is in Assam (0.6 years). This difference for a 25-year gap is highest in Assam with 11.5 years and lowest in Punjab with a negative difference of 1.7 years, which means that dynamic LEB is less than that of period LEB. This might be because, in Punjab, female mortality has increased more significantly from 1981-85 to 1996-2000 than 1996-2000 to 2006-2010, where the increase in life expectancy is approximately 3.3 years. One of the possible reasons for an increase in female mortality or decrease in female LEB for this state is due to the imbalance caused in sex ratio due to a strong preference for sons. According to the Census of India, the child sex ratio in Punjab was 908 in 1981, which gradually reduced to 875 in 1991 and then to 793 in 2001. Moreover, a 50-year interval produces the highest difference of 9.6 years both in Uttar Pradesh and Rajasthan and a lowest difference of 5.7 years is observed in the states of Assam and Kerala. Table 2 also shows that among females, the dynamic LEB for the period of 25 years is higher than the other two periods for all the states under study, except Punjab, where the dynamic LEB for a 50-year interval is highest. It is worth mentioning that the calculations for Punjab and Assam incorporated an adjustment in the population due to the creation of new states during the period 1960 to 1980. 


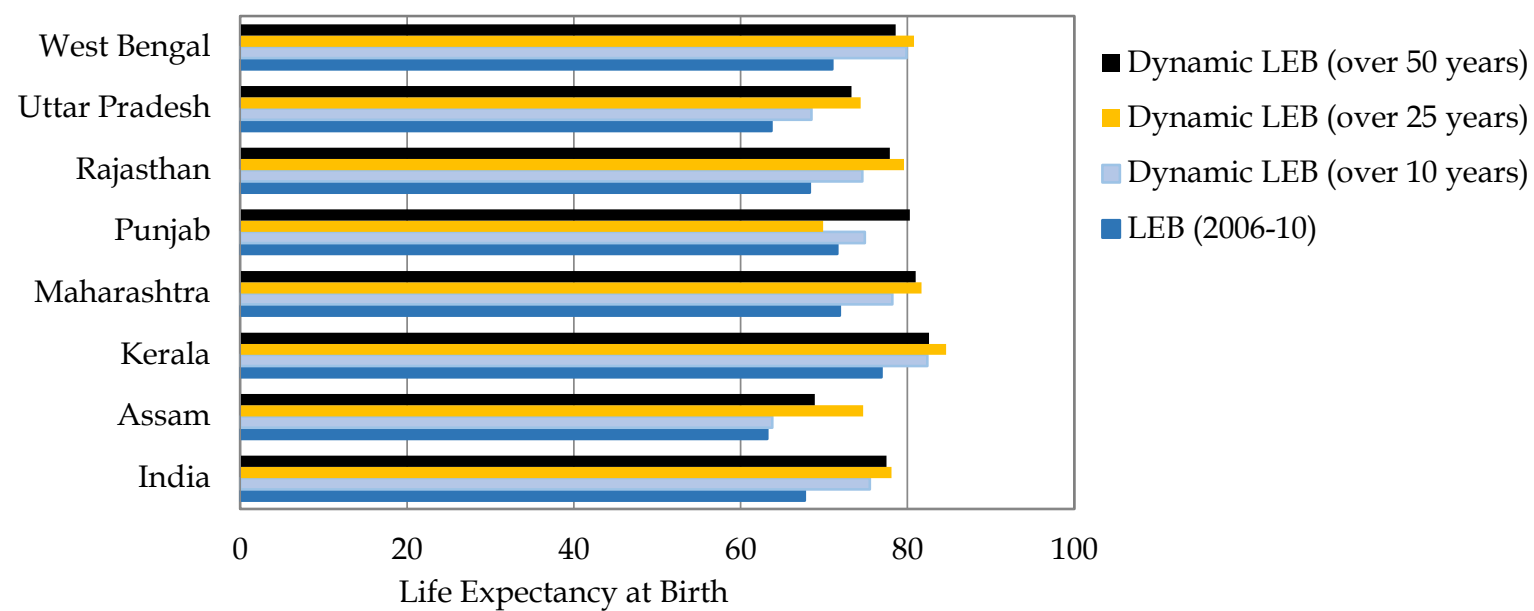

Figure 2: Dynamic and period life expectancy at birth, India and its selected states, (Females)

Disparities in LEB among males and females are clearly observed in Tables 1 and 2. The Sample Registration System report of India (2011) indicates that child mortality has continuously dropped from 110 per thousand live births in males and 126 in females in the year 1990 to 60 in males and 69 in females in 2009. This indicates that though the mortality differential among males and females has narrowed over the years, excess child mortality among females is still persisting in India, recording a gap of 9 per thousand live births in 2009. The evidence of an excess female mortality in childhood is typically understood as the consequence of parental discrimination against daughters in the provision of food and health care, even abusing the girl child within the household is also prevalent (Kuntla, Goli \& Jain, 2014).

Although child mortality remains significantly higher among the females of India, the improvements in overall mortality especially among adults have largely contributed to the increase in LEB in females as compared to males. Further, it has been observed that both under periodic and dynamic consideration, females are expected to live longer than their male counterparts in India and all the selected states. Tables 1 and 2 also reveal that there has been a faster decline in female mortality as compared to males over all the periods. These declines in dynamic probabilities of death and the corresponding male-female differential are depicted in Table 1 of the Appendix.

The increase in LEB under a dynamic scenario is attributed to a decline in child mortality and mortality in ages 40 and older. According to a recent by UNICEF et al. (2014), India's child mortality rate has dropped more than one half since 1990, but India still recorded the world's highest number of deaths among children below age five in 2013. The number of under-five deaths registered in India was 3.33 million in 1990, but it dropped to 1.34 million in 2013. Also the increasing level of urbanization in India tends to lower the death rate due to availability of better health facilities and sanitation. According to the Census of India, the portion of the population living in urban areas was $10.3 \%$ in 1911, and it increased to $27.8 \%$ by 2001 and $31.2 \%$ by 2011 . Among the states under consideration, Kerala had the highest urban population (47.7\%) in 2011 followed by Maharashtra (45.2\%) and Punjab (37.5\%). However, only $14.1 \%$ and $22.2 \%$ of population of Assam and Uttar Pradesh lived in urban areas, respectively. This might be one of the reasons that the people of these states experience a slower rate of mortality decline as compared to other states.

As discussed earlier, a comparison can also be made between period and dynamic LEB for 2009-2013 based on the rates of change in probabilities of death over 10 years, viz., 1999-2003. 
Across the states of India, there is almost 0.3 to 1.7 years of increase in LEB from 2006-2010 to 2009-2013 for males. This increase in LEB ranges from 0.6 to 1.9 years for females. Analogous to the period 1996-00 to 2006-2010, the highest difference in dynamic and period LEB for males is observed in Maharashtra (8.5 years) and Kerala (8.2 years). Here also Uttar Pradesh observed a negative difference of one and half years.

Table 3: Percentage of observed and dynamic temporary life expectancies to maximum possible years for populations ages 60 years and older, by selected state and sex

\begin{tabular}{|c|c|c|c|c|c|c|c|c|}
\hline \multirow{3}{*}{ State } & \multicolumn{4}{|c|}{ Males } & \multicolumn{4}{|c|}{ Females } \\
\hline & \multirow{2}{*}{$\begin{array}{c}\text { Percentage of } \\
\text { usual TLE }\end{array}$} & \multicolumn{3}{|c|}{$\begin{array}{c}\text { Percentage of } \\
\text { dynamic TLE based } \\
\text { over the previous }\end{array}$} & \multirow{2}{*}{$\begin{array}{c}\text { Percentage of } \\
\text { usual TLE }\end{array}$} & \multicolumn{3}{|c|}{$\begin{array}{c}\text { Percentage of } \\
\text { dynamic TLE based } \\
\text { over the previous }\end{array}$} \\
\hline & & $\begin{array}{c}10 \\
\text { years }\end{array}$ & $\begin{array}{c}25 \\
\text { years }\end{array}$ & $\begin{array}{c}50 \\
\text { years }\end{array}$ & & $\begin{array}{c}10 \\
\text { years }\end{array}$ & $\begin{array}{c}25 \\
\text { years }\end{array}$ & $\begin{array}{c}50 \\
\text { years }\end{array}$ \\
\hline All India & 38.7 & 49.3 & 54.5 & 52.3 & 42.6 & 53.2 & 57.9 & 55.4 \\
\hline Assam & 35.8 & 37.4 & 46.3 & 47.0 & 38.3 & 29.6 & 53.1 & 51.2 \\
\hline Kerala & 41.2 & 54.1 & 40.8 & 50.5 & 47.7 & 56.2 & 58.6 & 55.3 \\
\hline Maharashtra & 40.7 & 56.3 & 56.6 & 52.4 & 43.8 & 55.6 & 58.4 & 56.1 \\
\hline Punjab & 42.2 & 51.1 & 54.3 & 56.7 & 45.9 & 47.0 & 42.2 & 58.5 \\
\hline Rajasthan & 40.1 & 53.4 & 56.2 & 54.9 & 45.9 & 55.1 & 59.3 & 58.7 \\
\hline Uttar Pradesh & 36.8 & 37.0 & 46.5 & 50.9 & 41.0 & 46.8 & 57.1 & 54.7 \\
\hline West Bengal & 38.7 & 51.7 & 56.0 & 47.2 & 42.7 & 53.1 & 55.8 & 52.5 \\
\hline
\end{tabular}

The change in dynamic TLE was different in different phases of life. However, we have only examined the differences for the old age group as the effects of the dynamic calculations are mostly seen in this age group. To demonstrate the effect of changing mortality on the dynamic TLE in the old age group, we have plotted the probabilities of death under both usual and dynamic considerations for the period of 25 years for Indian males (Figure 3) and females (Figure 4). Figures 3 and 4 clearly indicate substantial differences in both usual and dynamic probabilities of death, which are greater in higher age groups. This confirms our assumption that the decline in old age mortality could be better explained through dynamic life tables.

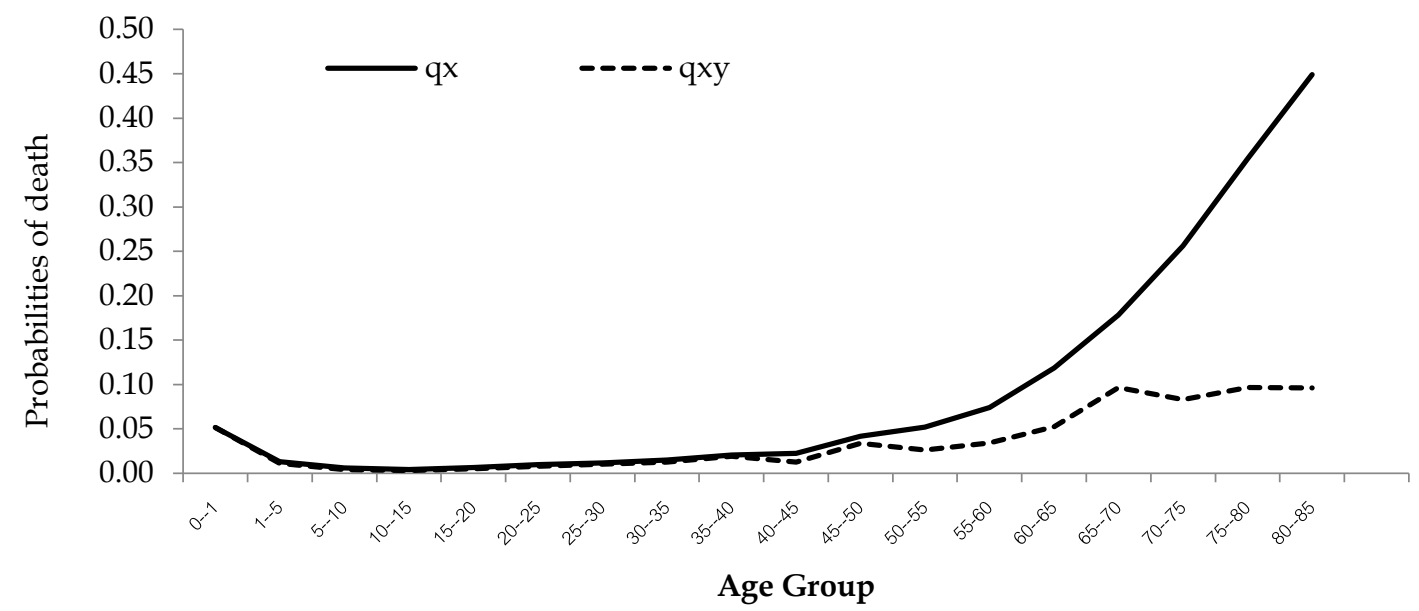

Figure 3: Probabilities of death under dynamic and usual consideration, India 2006-2010, over the previous period of 25 years (Males) 


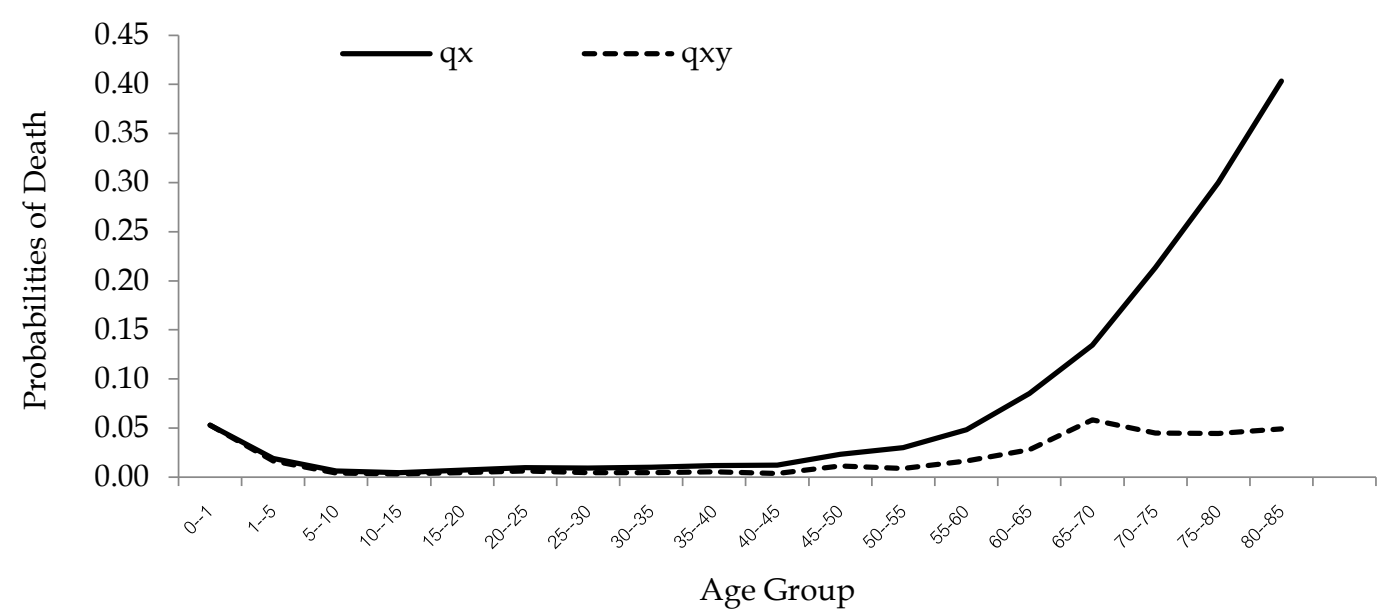

Figure 4: Probabilities of death under dynamic and usual consideration, India 2006-2010, over the previous period of 25 years (Females)

The values in Table 3 indicate the percentage of observed temporary life expectancy (TLE) for the 60 and older population to maximum possible years, which is 40 years, for the period 20062010 for India and all the selected states. The corresponding values of dynamic TLE over the period of 10, 25 and 50 years are also presented in the same table for both males and females. Generally, it is observed that there is an increase in TLE under dynamic consideration for India and the selected states over all the periods, except a few. The higher values of dynamic TLE in the old age group indicate that the reduction in mortality is faster in the corresponding intervals.

An analysis by the Central Statistics Office of the Government of India (2011) shows that the proportion of the population ages 60 or older in the total population has increased from $5.6 \%$ in 1961 to $7.4 \%$ in 2001. These percentages are usually higher among females than among males. With an improvement in sanitation conditions, nutrition and medical care (Medina, 1996), the incidence of death due to communicable diseases declines especially among children and the population moved to the mid stage of the epidemiological transition (United Nations, 2012). In the third stage, people survive to adulthood where the number of deaths due to non-communicable diseases (NCDs) rises rapidly and has been responsible for high mortality rates among the adults (Yadav \& Arokiasamy, 2013). However, the fourth stage of epidemiological transition is characterized by continued improvements in life expectancy, producing a shift in mortality due to NCD to progressively older ages (United Nations, 2012). As such, the improvement in probabilities of survival among populations ages 60 and older has been reflected in dynamic probabilities of death (see Appendix-1). This corresponds to an increase in the temporary life expectancy at old ages and also the expectation of life at birth under dynamic consideration.

\section{Conclusion}

Dynamic life expectancies vary with the choice of historical period, which may be important to include when presenting results (Denton \& Spencer 2011). This analysis shows that the rates at which the probabilities of death are changing across previous years have a significant effect 
on expectation of life at birth. Moreover, there has been a continuous decline in mortality among older men and women in India and all the states under consideration. This could also be observed from dynamic probabilities of death for the old age group. We also discovered that the rate at which mortality has been declining is fast among women during the 25-year gap in India and all the selected states, except in Punjab. The differences in dynamic LEB for 2006-2010 and 2009-2013 (i.e., over 10 years), seem to vary more in Rajasthan and West Bengal for males. However for females, these differences are higher in India and all the selected states, with the exception being Punjab and Rajasthan. This study suggests that dynamic consideration reveals the real situation of death more accurately by maintaining the rates of change of the period table probabilities over the previous years.

\section{References}

Arriaga, E. E. (1984). Measuring and explaining the change in life expectancies. Demography, 21(1), 83-96. DOI: https:/ / doi.org/10.2307/2061029

Bell, F.C. \& Miller, M. L. (2005). Life tables for the United States social security area 1900-2100. Actuarial Study 120. Washington, D.C.: Social Security Administration. Retrieved from https://www.ssa.gov/oact/NOTES/pdf_studies/study120.pdf

Bhat, P.N.M. (1987). Mortality in India: Levels, trends, and patterns. (Unpublished doctoral dissertation) University of Pennsylvania. Retrieved from http:/ / repository.upenn.edu/dissertations/AAI8725140/

Bhat, P.N.M \& Navaneetham, K. (1991). Recent trends in age specific mortality in India. Journal of Institute of Economic Research. 26 (1 \& 2). Retrieved from https://www.ncbi.nlm.nih.gov/pubmed/12317585

Central Statistics Office. (2011). Situation analysis of elderly in India. New Delhi: Ministry of Statistics and Programme Implementation. Retrieved from http://mospi.nic.in/sites/default/files/publication_reports/elderly_in_india.pdf

Chaurasia, A.R. (2010). Mortality transition in India 1970-2005. Asian Population Studies. 6(1), 47-68.

Debon. A., Montes, F. \& Sala, S. (2006). A comparison of models for dynamic life tables: Application to mortality data from the Valencia region (Spain). Lifetime Data Analysis, 12(2), 223-244. DOI: https://doi.org/10.1007/s10985-006-9005-1

Denton, F. T. \& Spencer, B. G. (2011). A dynamic extension of the period life table. Demographic Research, 24(24), 831-854. DOI: https:/ / doi.org/10.4054/demres.2011.24.34

Dubey, M. (2014). Trends and prospects of mortality by age and sex in India: 1991-2030. Retrieved from http:/ / paa2014.princeton.edu/abstracts/141995

Dyson T. (2008). India's demographic transition and its consequences for development. New Delhi: Institute of Economic Growth.

Kohli, K.L. (1977). Mortality in India: A state wise study. Sterling Publishers Pvt. Ltd.

Kuntla, S., Goli, S. \& Jain, K. (2014). Explaining gender differentials in child mortality in India: Trends and determinants. International Journal of Population Research, 2014, 1-7. DOI: https://doi.org/10.1155/2014/649741

Lee R.D. \& Carter, L. R. (1992). Modelling and forecasting U.S. mortality. Journal of the American Statistical Association, 87 (419), 659-671. DOI: https:/ / doi.org/10.2307/2290201

Medina, S. (1996). Implementing a new indicator of social development in Mexico: Literate life expectancy (LLE). Laxenburg, Austria: International Institute of Applied System Analysis. Retrieved from http:/ / pure.iiasa.ac.at/4924/1/WP-96-103.pdf

Navaneetham K. (1993). Mortality trends in India: An analysis of regional and temporal variations. Demography India, 22(1), 53-63.

Panigrahy R. L. (2006). Consequences of demographic transition in India. New Delhi: Discovery Publishing House.

Pollard J. H. (1988). On decomposition of changes in expectation of life and differentials in life expectancy. Demography, 25 (2), 265-276. DOI: https:/ / doi.org/10.2307/2061293 
Registrar General of India. (1981-85, 1996-00, 1999-03, 2006-2010, 2009-13). SRS-based abridged life tables of India and the major states. New Delhi: Registrar General of India.

Registrar General of India. (1970-75, 2011, 2014). SRS Bulletins. New Delhi: Registrar General of India.

Richards, H. \& Donaldson, M. (2010). Life and worklife expectancies. Tucson, Arizona: Lawyers and Judges Publishing Company, Inc.

Saikia, N., Jasilionis, D., Ram, F. \& Shkolnikov, V. (2009). Trends in geographical mortality differentials in India. Retrieved from Max Plank Institute for Demographic Research website http:/ / www.demogr.mpg.de/papers/working/wp-2009-013.pdf

Schoen R. \& Canudas-Romo, V. (2005). Changing mortality and average cohort life expectancy. Demographic Research, 13, 117-142. DOI: https://doi.org/10.4054/demres.2005.13.5

Singh A, Pathak P. K., Chauhan R. K. \& Pan W. (2011). Infant and child mortality in India in the last two decades: A geospatial analysis. PLoS ONE 6(11), e26856. DOI: https://doi.org/10.1371/journal.pone.0026856

Thomas, M. B. \& James, K. S. (2014). Changing mortality and human longevity in Kerala: Are they leading to the advanced stages. Global Health Action. 7(1), 22938. DOI: https://doi.org/10.3402/gha.v7.22938

United Nations. (2012). Changing levels and trends in mortality: The role of patterns of death by cause. New York: Department of Economic and Social Affairs, Population Division, United Nations Publication. Retrieved from http://www.un.org/esa/population/publications/levelsandtrendsinmortality/Changing\%20le vels \% 20and \%20trends\%20in \%20mortality.pdf

UNICEF, World Health Organization, The World Bank \& United Nations Population Division. (2014). Levels and trends in child mortality report 2014: Estimates developed by the UN interagency group for child mortality estimation. New York: UNICEF. Retrieved from https://www.unicef.org/media/files/Levels_and_Trends_in_Child_Mortality_2014.pdf

Yadav, S. \& Arokiasamy, P. (2013). Causes of death and mortality transition in India. Retrieved from the International Union for Scientific Study of Population website https://iussp.org/sites/default/files/event_call_for_papers/Causes \%20of\%20Death\%20and \%2 0Mortality\%20Transition\%20in\%20India_1.pdf

Yamunadevi, A. \& Sulaja, S. (2016). Old age mortality in India: An exploration from life expectancy at age 60. International Journal of Asian Social Science. 6(12), 698-704. DOI:

https:/ / doi.org/10.18488/journal.1/2016.6.12/1.12.698.704 
Appendix 1: Probabilities of death under dynamic and period life table, for India and its selected states, by sex

\begin{tabular}{|c|c|c|c|c|c|c|c|c|}
\hline \multirow{3}{*}{$\begin{array}{l}\text { Age } \\
\text { group }\end{array}$} & \multirow{2}{*}{\multicolumn{2}{|c|}{$\begin{array}{l}\text { Probabilities of death }\left({ }_{n} q_{x}\right) \text {, } \\
\text { 2006-2010 }\end{array}$}} & \multicolumn{6}{|c|}{$\begin{array}{l}\text { Dynamic probabilities of death based on the rates of change of }{ }_{n} q_{x} \\
\text { over the previous }\end{array}$} \\
\hline & & & \multicolumn{2}{|c|}{10 years } & \multicolumn{2}{|c|}{25 years } & \multicolumn{2}{|c|}{50 years } \\
\hline & Male & Female & Male & Female & Male & Female & Male & Female \\
\hline \multicolumn{9}{|c|}{ India } \\
\hline $1-5$ & 0.01317 & 0.01901 & 0.01150 & 0.01644 & 0.01145 & 0.01662 & 0.01200 & 0.01760 \\
\hline $5-10$ & 0.00588 & 0.00608 & 0.00440 & 0.00387 & 0.00441 & 0.00434 & 0.00494 & 0.00486 \\
\hline $10-15$ & 0.00429 & 0.00454 & 0.00306 & 0.00305 & 0.00313 & 0.00327 & 0.00330 & 0.00319 \\
\hline $15-20$ & 0.00653 & 0.00718 & 0.00486 & 0.00382 & 0.00508 & 0.00462 & 0.00438 & 0.00494 \\
\hline $20-25$ & 0.00970 & 0.00956 & 0.00760 & 0.00436 & 0.00777 & 0.00618 & 0.00578 & 0.00536 \\
\hline $25-30$ & 0.01173 & 0.00921 & 0.00809 & 0.00348 & 0.01018 & 0.00448 & 0.00577 & 0.00348 \\
\hline $30-35$ & 0.01504 & 0.01015 & 0.01217 & 0.00371 & 0.01285 & 0.00469 & 0.00631 & 0.00282 \\
\hline $35-40$ & 0.02079 & 0.01193 & 0.01989 & 0.00587 & 0.01941 & 0.00541 & 0.00795 & 0.00257 \\
\hline $40-45$ & 0.02246 & 0.01243 & 0.00837 & 0.00217 & 0.01244 & 0.00371 & 0.00654 & 0.00197 \\
\hline $45-50$ & 0.04158 & 0.02334 & 0.04861 & 0.01280 & 0.03367 & 0.01129 & 0.01491 & 0.00453 \\
\hline $50-55$ & 0.05216 & 0.02992 & 0.02109 & 0.00477 & 0.02619 & 0.00901 & 0.01614 & 0.00494 \\
\hline $55-60$ & 0.07417 & 0.04835 & 0.02298 & 0.00851 & 0.03412 & 0.01666 & 0.02195 & 0.00828 \\
\hline $60-65$ & 0.11853 & 0.08520 & 0.04498 & 0.02607 & 0.05276 & 0.02796 & 0.04224 & 0.01984 \\
\hline $65-70$ & 0.17807 & 0.13455 & 0.08540 & 0.05189 & 0.09655 & 0.05837 & 0.07329 & 0.03855 \\
\hline \multicolumn{9}{|c|}{ Assam* } \\
\hline $1-5$ & 0.02127 & 0.02700 & 0.01885 & 0.02471 & 0.01914 & 0.02455 & 0.03225 & 0.03191 \\
\hline $5-10$ & 0.00941 & 0.00866 & 0.00614 & 0.00510 & 0.00729 & 0.00657 & 0.00963 & 0.00912 \\
\hline $10-15$ & 0.00563 & 0.00673 & 0.00352 & 0.00406 & 0.00401 & 0.00531 & 0.00547 & 0.00498 \\
\hline $15-20$ & 0.01089 & 0.01109 & 0.02320 & 0.00657 & 0.01248 & 0.00863 & 0.00680 & 0.00358 \\
\hline $20-25$ & 0.00881 & 0.01153 & 0.00318 & 0.00478 & 0.00522 & 0.00646 & 0.00721 & 0.00518 \\
\hline $25-30$ & 0.01578 & 0.01228 & 0.01250 & 0.00570 & 0.01455 & 0.00600 & 0.00740 & 0.00343 \\
\hline $30-35$ & 0.01715 & 0.01607 & 0.01171 & 0.00487 & 0.01506 & 0.00799 & 0.01034 & 0.00415 \\
\hline $35-40$ & 0.02025 & 0.01804 & 0.00713 & 0.01166 & 0.01554 & 0.00765 & 0.01283 & 0.00370 \\
\hline $40-45$ & 0.03357 & 0.01721 & 0.02184 & 0.00097 & 0.02553 & 0.00375 & 0.01589 & 0.00632 \\
\hline $45-50$ & 0.05355 & 0.04278 & 0.03258 & 0.04402 & 0.04277 & 0.02642 & 0.01428 & 0.00477 \\
\hline $50-55$ & 0.06456 & 0.04467 & 0.02859 & 0.00943 & 0.02191 & 0.01247 & 0.01835 & 0.00452 \\
\hline $55-60$ & 0.10919 & 0.07474 & 0.10154 & 0.01796 & 0.05950 & 0.02962 & 0.03544 & 0.01349 \\
\hline $60-65$ & 0.13300 & 0.09114 & 0.02718 & 0.00805 & 0.04859 & 0.01706 & 0.02612 & 0.01467 \\
\hline $65-70$ & 0.23700 & 0.20962 & 0.28998 & 0.50242 & 0.15589 & 0.11273 & 0.06624 & 0.03248 \\
\hline \multicolumn{9}{|c|}{ Kerala } \\
\hline $1-5$ & 0.00184 & 0.00224 & 0.00142 & 0.00189 & 0.00146 & 0.00183 & 0.00156 & 0.00189 \\
\hline $5-10$ & 0.00100 & 0.00090 & 0.00021 & 0.00019 & 0.00060 & 0.00058 & 0.00072 & 0.00059 \\
\hline $10-15$ & 0.00130 & 0.00125 & 0.00069 & 0.00063 & 0.00083 & 0.00083 & 0.00082 & 0.00075 \\
\hline $15-20$ & 0.00300 & 0.00230 & 0.00269 & 0.00135 & 0.00189 & 0.00151 & 0.00154 & 0.00107 \\
\hline $20-25$ & 0.00534 & 0.00374 & 0.00449 & 0.00256 & 0.00414 & 0.00231 & 0.00249 & 0.00145 \\
\hline $25-30$ & 0.00817 & 0.00354 & 0.00753 & 0.00170 & 0.00611 & 0.00167 & 0.00355 & 0.00093 \\
\hline $30-35$ & 0.00792 & 0.00349 & 0.00347 & 0.00087 & 0.00411 & 0.00121 & 0.00256 & 0.00063 \\
\hline $35-40$ & 0.01322 & 0.00573 & 0.01525 & 0.00374 & 0.01220 & 0.00232 & 0.00450 & 0.00099 \\
\hline $40-45$ & 0.01554 & 0.00663 & 0.00664 & 0.00146 & 0.00589 & 0.00219 & 0.00432 & 0.00088 \\
\hline $45-50$ & 0.03071 & 0.01178 & 0.02454 & 0.00837 & 0.02190 & 0.00696 & 0.01101 & 0.00176 \\
\hline $50-55$ & 0.04425 & 0.01480 & 0.02886 & 0.00206 & 0.02212 & 0.00459 & 0.01597 & 0.00181 \\
\hline $55-60$ & 0.06132 & 0.02745 & 0.02340 & 0.01930 & 0.02710 & 0.01303 & 0.02101 & 0.00411 \\
\hline $60-65$ & 0.09559 & 0.04582 & 0.01897 & 0.00722 & 0.05786 & 0.01412 & 0.03845 & 0.00852 \\
\hline $65-70$ & 0.14331 & 0.08600 & 0.03793 & 0.02459 & 0.09704 & 0.04629 & 0.06651 & 0.02432 \\
\hline \multicolumn{9}{|c|}{ Maharashtra } \\
\hline $1-5$ & 0.00685 & 0.00760 & 0.00624 & 0.00652 & 0.00587 & 0.00637 & 0.00609 & 0.00192 \\
\hline $5-10$ & 0.00319 & 0.00265 & 0.00227 & 0.00180 & 0.00226 & 0.00177 & 0.00253 & 0.00192 \\
\hline $10-15$ & 0.00359 & 0.00315 & 0.00371 & 0.00283 & 0.00280 & 0.00233 & 0.00256 & 0.00254 \\
\hline $15-20$ & 0.00449 & 0.00469 & 0.00357 & 0.00181 & 0.00311 & 0.00283 & 0.00273 & 0.00293 \\
\hline $20-25$ & 0.00842 & 0.00613 & 0.00753 & 0.00279 & 0.00717 & 0.00350 & 0.00521 & 0.00249 \\
\hline $25-30$ & 0.01208 & 0.00653 & 0.00893 & 0.00240 & 0.01096 & 0.00295 & 0.00678 & 0.00273 \\
\hline $30-35$ & 0.01425 & 0.00827 & 0.00879 & 0.00505 & 0.01119 & 0.00356 & 0.00662 & 0.00314 \\
\hline
\end{tabular}




\begin{tabular}{|c|c|c|c|c|c|c|c|c|}
\hline \multirow{3}{*}{$\begin{array}{l}\text { Age } \\
\text { group }\end{array}$} & \multirow{2}{*}{\multicolumn{2}{|c|}{$\begin{array}{l}\text { Probabilities of death }\left({ }_{\mathrm{n}} \mathrm{q}_{\mathrm{x}}\right) \text {, } \\
\text { 2006-2010 }\end{array}$}} & \multirow{2}{*}{\multicolumn{6}{|c|}{$\begin{array}{l}\text { Dynamic probabilities of death based on the rates of change of }{ }_{n} q_{x} \\
\text { over the previous } \\
10 \text { years }\end{array}$}} \\
\hline & & & & & & & & \\
\hline & Male & Female & Male & Female & Male & Female & Male & Female \\
\hline $35-40$ & 0.02201 & 0.01084 & 0.02164 & 0.01759 & 0.02129 & 0.00481 & 0.01027 & 0.00140 \\
\hline $40-45$ & 0.02059 & 0.00856 & 0.00450 & 0.00062 & 0.01136 & 0.00174 & 0.00667 & 0.00404 \\
\hline $45-50$ & 0.03772 & 0.01869 & 0.03666 & 0.00838 & 0.03514 & 0.00935 & 0.01519 & 0.00433 \\
\hline $50-55$ & 0.04841 & 0.02442 & 0.03337 & 0.00325 & 0.03017 & 0.00923 & 0.08126 & 0.00857 \\
\hline $55-60$ & 0.07130 & 0.04343 & 0.02374 & 0.01578 & 0.03619 & 0.01939 & 0.02471 & 0.02012 \\
\hline $60-65$ & 0.09826 & 0.07835 & 0.01296 & 0.02562 & 0.03213 & 0.03279 & 0.03458 & 0.03291 \\
\hline $65-70$ & 0.16000 & 0.11833 & 0.03519 & 0.03037 & 0.06919 & 0.04855 & 0.07094 & 0.07045 \\
\hline \multicolumn{9}{|c|}{ Punjab * } \\
\hline $1-5$ & 0.00721 & 0.01281 & 0.00645 & 0.01160 & 0.00649 & 0.01132 & 0.00812 & 0.01237 \\
\hline $5-10$ & 0.00429 & 0.00364 & 0.00522 & 0.00242 & 0.00344 & 0.00264 & 0.00403 & 0.00444 \\
\hline $10-15$ & 0.00324 & 0.00280 & 0.00312 & 0.00204 & 0.00240 & 0.00175 & 0.00289 & 0.00223 \\
\hline $15-20$ & 0.00663 & 0.00683 & 0.00541 & 0.00821 & 0.00521 & 0.00531 & 0.00609 & 0.00515 \\
\hline $20-25$ & 0.01055 & 0.00613 & 0.00805 & 0.00298 & 0.01059 & 0.00368 & 0.00883 & 0.00450 \\
\hline $25-30$ & 0.01484 & 0.00772 & 0.01086 & 0.00452 & 0.01579 & 0.00462 & 0.00940 & 0.00449 \\
\hline $30-35$ & 0.01676 & 0.00583 & 0.01215 & 0.00180 & 0.01573 & 0.00182 & 0.01148 & 0.00263 \\
\hline $35-40$ & 0.02108 & 0.00777 & 0.02446 & 0.00195 & 0.01970 & 0.00272 & 0.00997 & 0.00226 \\
\hline $40-45$ & 0.02402 & 0.01099 & 0.00733 & 0.00539 & 0.01859 & 0.00563 & 0.00939 & 0.00248 \\
\hline $45-50$ & 0.04258 & 0.01647 & 0.08944 & 0.00247 & 0.07363 & 0.01346 & 0.02021 & 0.00397 \\
\hline $50-55$ & 0.05225 & 0.02657 & 0.03422 & 0.00240 & 0.05558 & 0.01107 & 0.01774 & 0.00510 \\
\hline $55-60$ & 0.07040 & 0.05002 & 0.05257 & 0.02385 & 0.13125 & 0.03809 & 0.01943 & 0.00753 \\
\hline $60-65$ & 0.10119 & 0.07384 & 0.11914 & 0.04205 & 0.09427 & 0.06411 & 0.03276 & 0.01421 \\
\hline $65-70$ & 0.13779 & 0.11523 & 0.05029 & 0.11168 & 0.13001 & 0.13863 & 0.03977 & 0.02389 \\
\hline \multicolumn{9}{|c|}{ Rajasthan } \\
\hline $1-5$ & 0.01250 & 0.02514 & 0.01023 & 0.02209 & 0.01050 & 0.02387 & 0.01156 & 0.02396 \\
\hline $5-10$ & 0.00722 & 0.00514 & 0.00739 & 0.00323 & 0.00558 & 0.00427 & 0.00705 & 0.00425 \\
\hline $10-15$ & 0.00344 & 0.00424 & 0.00243 & 0.00289 & 0.00205 & 0.00364 & 0.00279 & 0.00309 \\
\hline $15-20$ & 0.00618 & 0.00643 & 0.00703 & 0.00380 & 0.00592 & 0.00521 & 0.00463 & 0.00414 \\
\hline $20-25$ & 0.00807 & 0.00688 & 0.00537 & 0.00213 & 0.00542 & 0.00430 & 0.00587 & 0.00352 \\
\hline $25-30$ & 0.01030 & 0.00906 & 0.00510 & 0.00565 & 0.00780 & 0.00750 & 0.00705 & 0.00393 \\
\hline $30-35$ & 0.01238 & 0.00742 & 0.01107 & 0.00110 & 0.00733 & 0.00346 & 0.00738 & 0.00205 \\
\hline $35-40$ & 0.01701 & 0.01074 & 0.01366 & 0.00853 & 0.01145 & 0.00979 & 0.00888 & 0.00262 \\
\hline $40-45$ & 0.01952 & 0.01154 & 0.00553 & 0.00535 & 0.00881 & 0.00848 & 0.00709 & 0.00202 \\
\hline $45-50$ & 0.03512 & 0.01927 & 0.04713 & 0.01040 & 0.01970 & 0.01506 & 0.01405 & 0.00345 \\
\hline $50-55$ & 0.04969 & 0.02475 & 0.01227 & 0.01048 & 0.01919 & 0.01755 & 0.01762 & 0.00365 \\
\hline $55-60$ & 0.06401 & 0.03207 & 0.01053 & 0.00267 & 0.01592 & 0.01187 & 0.01883 & 0.00357 \\
\hline $60-65$ & 0.10749 & 0.06553 & 0.03358 & 0.01055 & 0.02773 & 0.03156 & 0.03563 & 0.01079 \\
\hline $65-70$ & 0.15930 & 0.10050 & 0.03924 & 0.02080 & 0.05230 & 0.05352 & 0.05394 & 0.01802 \\
\hline \multicolumn{9}{|c|}{ Uttar Pradesh } \\
\hline $1-5$ & 0.01854 & 0.03208 & 0.01629 & 0.02812 & 0.01639 & 0.02848 & 0.01692 & 0.03003 \\
\hline $5-10$ & 0.00757 & 0.00871 & 0.00604 & 0.00569 & 0.00565 & 0.00617 & 0.00675 & 0.00743 \\
\hline $10-15$ & 0.00464 & 0.00514 & 0.00302 & 0.00301 & 0.00326 & 0.00346 & 0.00357 & 0.00356 \\
\hline $15-20$ & 0.00703 & 0.00857 & 0.00444 & 0.00449 & 0.00493 & 0.00572 & 0.00515 & 0.00553 \\
\hline $20-25$ & 0.01079 & 0.01326 & 0.00771 & 0.00596 & 0.00866 & 0.00773 & 0.00775 & 0.00823 \\
\hline $25-30$ & 0.01233 & 0.01316 & 0.00875 & 0.00538 & 0.01047 & 0.00669 & 0.00723 & 0.00651 \\
\hline $30-35$ & 0.01618 & 0.01346 & 0.01529 & 0.00382 & 0.01473 & 0.00615 & 0.00825 & 0.00518 \\
\hline $35-40$ & 0.02490 & 0.01592 & 0.03898 & 0.00866 & 0.02723 & 0.00816 & 0.01230 & 0.00510 \\
\hline $40-45$ & 0.02539 & 0.01558 & 0.01666 & 0.00324 & 0.01479 & 0.00533 & 0.00904 & 0.00347 \\
\hline $45-50$ & 0.04388 & 0.02642 & 0.07491 & 0.02600 & 0.03119 & 0.01298 & 0.01768 & 0.00642 \\
\hline $50-55$ & 0.05562 & 0.03462 & 0.03642 & 0.00702 & 0.02706 & 0.01251 & 0.01938 & 0.00714 \\
\hline $55-60$ & 0.07688 & 0.05035 & 0.03530 & 0.00986 & 0.03185 & 0.01408 & 0.02417 & 0.00947 \\
\hline $60-65$ & 0.13470 & 0.09440 & 0.10987 & 0.04880 & 0.07423 & 0.02976 & 0.05539 & 0.02473 \\
\hline $65-70$ & 0.19938 & 0.14753 & 0.23858 & 0.07846 & 0.12144 & 0.06645 & 0.09074 & 0.04501 \\
\hline \multicolumn{9}{|c|}{ West Bengal } \\
\hline $1-5$ & 0.00824 & 0.00681 & 0.00691 & 0.00528 & 0.00690 & 0.00552 & 0.00746 & 0.00606 \\
\hline $5-10$ & 0.00344 & 0.00384 & 0.00224 & 0.00240 & 0.00121 & 0.00247 & 0.00290 & 0.00315 \\
\hline $10-15$ & 0.00404 & 0.00389 & 0.00347 & 0.00252 & 0.00302 & 0.00269 & 0.00323 & 0.00297 \\
\hline
\end{tabular}




\begin{tabular}{|c|c|c|c|c|c|c|c|c|}
\hline \multirow{3}{*}{$\begin{array}{l}\text { Age } \\
\text { group }\end{array}$} & \multirow{2}{*}{\multicolumn{2}{|c|}{$\begin{array}{l}\text { Probabilities of death }\left({ }_{n} q_{x}\right) \text {, } \\
\text { 2006-2010 }\end{array}$}} & \multicolumn{6}{|c|}{$\begin{array}{l}\begin{array}{l}\text { Dynamic probabilities of death based on the rates of change of } \mathrm{nq}_{\mathrm{x}} \\
\text { over the previous }\end{array}\end{array}$} \\
\hline & & & \multicolumn{2}{|c|}{10 years } & \multicolumn{2}{|c|}{25 years } & \multicolumn{2}{|c|}{50 years } \\
\hline & Male & Female & Male & Female & Male & Female & Male & Female \\
\hline $15-20$ & 0.00549 & 0.00603 & 0.00404 & 0.00241 & 0.00392 & 0.00312 & 0.00351 & 0.00389 \\
\hline $20-25$ & 0.00747 & 0.00698 & 0.00622 & 0.00204 & 0.00575 & 0.00334 & 0.00381 & 0.00332 \\
\hline $25-30$ & 0.00787 & 0.00648 & 0.00479 & 0.00274 & 0.00559 & 0.00242 & 0.00281 & 0.00201 \\
\hline $30-35$ & 0.01129 & 0.00673 & 0.00921 & 0.00181 & 0.00868 & 0.00197 & 0.00345 & 0.00144 \\
\hline $35-40$ & 0.01548 & 0.01025 & 0.01787 & 0.00525 & 0.01123 & 0.00409 & 0.00425 & 0.00207 \\
\hline $40-45$ & 0.01815 & 0.01154 & 0.00822 & 0.00286 & 0.00792 & 0.00299 & 0.00416 & 0.00186 \\
\hline $45-50$ & 0.03598 & 0.02119 & 0.04359 & 0.00784 & 0.01955 & 0.00747 & 0.01154 & 0.00421 \\
\hline $50-55$ & 0.03998 & 0.02579 & 0.00568 & 0.00253 & 0.01047 & 0.00423 & 0.01045 & 0.00436 \\
\hline $55-60$ & 0.07104 & 0.04822 & 0.01787 & 0.00331 & 0.03168 & 0.01597 & 0.02264 & 0.01013 \\
\hline $60-65$ & 0.11116 & 0.07990 & 0.02064 & 0.01309 & 0.03800 & 0.02698 & 0.04605 & 0.02240 \\
\hline $65-70$ & 0.18405 & 0.13987 & 0.07235 & 0.07273 & 0.09237 & 0.06914 & 0.10822 & 0.05787 \\
\hline
\end{tabular}

*Probabilities of death in Punjab and Assam for 50 years gap are based on the adjusted values to account for the creation of new states.

Note: The values of dynamic probabilities of death over all the periods for the age group $0-1$ are not shown in the table as these were the same as the corresponding values of the period life table. This is an obvious result and could be verified through the given formula of dynamic probabilities of death.

Appendix 2: Period life expectancy at birth for 2009-2013 and dynamic life expectancy at birth based on the rates of change of probabilities of death over the previous 10 years (1999-2003), for India and the selected states and for both males and females

\begin{tabular}{|c|c|c|c|c|}
\hline \multirow{2}{*}{ States } & \multicolumn{2}{|c|}{ Males } & \multicolumn{2}{|c|}{ Females } \\
\hline & Period LEB & Dynamic LEB & Period LEB & Dynamic LEB \\
\hline India & 65.8 & 70.3 & 69.3 & 74.9 \\
\hline Assam & 61.9 & 65.0 & 65.1 & 71.9 \\
\hline Kerala & 71.8 & 80.0 & 77.8 & 88.6 \\
\hline Maharashtra & 69.4 & 77.9 & 73.4 & 78.3 \\
\hline Punjab & 69.1 & 69.9 & 73.4 & 75.2 \\
\hline Rajasthan & 65.4 & 66.7 & 70.0 & 72.6 \\
\hline Uttar Pradesh & 62.5 & 61.0 & 65.2 & 69.4 \\
\hline West Bengal & 68.5 & 72.6 & 71.6 & 76.6 \\
\hline
\end{tabular}

